\title{
Watch and wait strategies for rectal cancer A systematic review
}

\section{In Ja Park}

Department of Colon and Rectal Surgery, Asan Medical Center, University of Ulsan College of Medicine, Seoul, Korea

Received: October 21, 2021

Revised: November 17, 2021

Accepted: December 6, 2021

Corresponding author:

In Ja Park

Department of Colon and Rectal Surgery, Asan Medical Center, University of Ulsan College of Medicine, 88 Olympic-ro 43-gil, Songpa-gu, Seoul 05505, Korea Tel: +82-2-3010-3937

E-mail:ipark@amc.seoul.kr

\begin{abstract}
Watch and wait (WW) strategies have been suggested for patients with clinical complete regression (CCR). The WW approach was first introduced by Habr-Gama in patients with cCR after neoadjuvant treatment. Actually, it is not "no surgery" but "deferral of surgery"; therefore, the WW approach or non-operative management is a representative term currently. The number of publications regarding WW for rectal cancer has increased abruptly. We conducted a systematic review of PubMed for literature published on WW. It is now one of the most interesting issues in rectal cancer treatment. Many studies have reported comparable overall survival with WW and radical resection. However, a high local regrowth rate is a problem, and proper salvage management is the main concern in the WW approach. Adequate patient selection is necessary to achieve favorable oncologic outcomes. However, the appropriate definition and diagnostic method for CCR have not yet been clearly defined. Indeed, advances in local control have not translated into overall survival improvement, and many efforts have been made to improve distant metastasis control and overall survival and improve clinical response to preoperative chemoradiotherapy. In this review, oncologic outcomes, ongoing efforts to improve oncologic outcomes, and limitations for clinical practice were evaluated and described.
\end{abstract}

Keywords: Clinical complete regression; Neoadjuvant therapy; Rectal neoplasms; Watch and wait

\section{INTRODUCTION}

Over the past 100 years, the field of rectal cancer surgery has undergone various surgical developments. In addition, there have been huge changes in technical and oncological aspects accompanied by preoperative chemoradiotherapy (PCRT) during the last 20 years [1-5]. The introduction of PCRT has brought about the most innovative changes in the treatment of rectal cancer. PCRT, which is focused on the reduction of local recurrence, has shown differences in oncological outcomes according to the regression of various tumors after PCRT, which influences the strategy of subsequent surgical treatment.

Total mesorectal excision (TME), an approved standard surgical treatment for rectal cancer, is associated with perioperative morbidity and impaired quality of life [6-9]. Therefore, treat-
This is an Open Access article distributed under the terms of the Creative Commons Attribution Non-Commercial License (https:// creativecommons.org/licenses/ by-nc/4.0/). 
ment strategies that maintain quality of life without compromising oncologic outcomes have gained attention gradually. In patients with complete regression after PCRT (15\% to 30\% of the patients), organ-preserving approaches, such as local excision and watch and wait (WW), have been attempted based on several studies reporting favorable oncologic outcomes in these patients. Local excision is advantageous in that it confirms the pathologic T stage. Pathologic lymph node metastasis status, however, cannot be detected. Furthermore, some studies have reported that a long interval between completion of PCRT and surgical intervention improved tumor response; therefore, WW, which defers surgery with close surveillance, has recently gained more support [10]. Various efforts, such as total neoadjuvant therapy (TNT), are being attempted to obtain clinical complete regression (cCR) in patients.

However, the diagnostic method to determine whether the patient is suitable for the application of WW is still inaccurate and has limitations in that the standards for subsequent surveillance methods are not clear. In this review, the oncological results of the application of WW to rectal cancer patients who underwent PCRT and the evidence for the applicable patient diagnosis and subsequent surveillance are investigated.

\section{METHODS}

The PubMed database was queried using the following search terms: (('rectal cancer") OR ("rectal neoplasm")) AND (("preoperative chemoradiotherapy") OR ("neoadjuvant therapy")) OR ("neoadjvuant chemoradiotherapy") AND (("complete regression") OR ("good response")) AND ("“Watch and wait") OR (Non-operative managment) OR (Deferral of Surgery) OR ("Wait and see") OR ("Organ preservation")). All literature published prior to September of 2021 was then screened. Articles were excluded if they were not available abstract in English. All articles were screened by one author (IJP). Articles were reviewed and contents were described as five sections based on their reported data.

\section{ONCOLOGIC OUTCOMES OF WW}

WW for patients with clinical complete or near-complete regression after PCRT provides the undeniable benefits of avoiding surgical complications and deterioration of quality of life. Though these advantages are important, the oncological outcomes are the prime focus of WW and should not be compromised. Until now, TME is the standard surgery for rectal cancer, so the oncological outcome should not deteriorate compared to that with TME. In the case of pathologic complete regression ( $\mathrm{pCR}$ ) after PCRT, radical resection has

Table 1. Oncologic outcomes of watch and wait approaches for rectal cancer treated with preoperative chemoradiotherapy: comparison with radical resection

\begin{tabular}{|c|c|c|c|c|c|c|c|c|c|c|c|}
\hline \multirow{2}{*}{ Study } & \multirow{2}{*}{ Year } & \multicolumn{2}{|c|}{ Number } & \multicolumn{2}{|c|}{$\begin{array}{l}\text { FU duration } \\
\text { (mo) }\end{array}$} & \multicolumn{2}{|c|}{$\begin{array}{l}\qquad \text { Local } \\
\text { recurrence (\%) }\end{array}$} & \multicolumn{2}{|c|}{$\begin{array}{c}\text { Distant } \\
\text { metastasis (\%) }\end{array}$} & \multicolumn{2}{|c|}{$\begin{array}{c}\text { Cancer-related } \\
\text { death (\%) }\end{array}$} \\
\hline & & WW & RS & WW & RS & WW & RS & WW & RS & WW & RS \\
\hline Habr-Gama et al. [18] & 2004 & 71 & 22 & 57.3 & 48 & 2.8 & 0 & 4.2 & 13.6 & 0 & 9.1 \\
\hline Maas et al. [22] & 2011 & 21 & 20 & 25 & 35 & 4.7 & 0 & 0 & 5 & - & - \\
\hline Smith et al. [24] & 2012 & 32 & 57 & 28 & 43 & 18.8 & 0 & 9.3 & 5.3 & 3.2 & 0 \\
\hline Ayloor Seshadri et al. [16] & 2013 & 23 & 10 & 72 & 72 & 30.4 & 0 & 13 & 20 & - & - \\
\hline Lee et al. [20] & 2015 & 8 & 28 & 41 & 41 & 25 & 3.5 & 0 & 10.7 & 0 & 10.7 \\
\hline Li et al. [21] & 2015 & 147 & 51 & 58 & 58 & & & & & & \\
\hline Araujo et al. [15] & 2015 & 42 & 69 & 47.7 & 46.7 & 19 & 4.7 & & & $62^{\text {a) }}$ & $82.7^{a)}$ \\
\hline Renehan et al. [23] & 2016 & 129 & 109 & 33 & 33 & - & - & - & - & $96^{\text {b) }}$ & $87^{\text {b) }}$ \\
\hline Lai et al. [19] & 2016 & 18 & 26 & 49 & 42 & 11.1 & 0 & - & - & - & - \\
\hline Yeom et al. [26] & 2019 & 15 & 129 & 60 & 60 & 40 & 12.4 & 26.7 & 3.8 & - & - \\
\hline Beard et al. [17] & 2020 & 53 & 42 & - & - & & & & & $95^{\mathrm{b})}$ & $100^{b)}$ \\
\hline Wang et al. [25] & 2020 & 59 & 179 & 60 & 60 & 11.9 & 0.5 & 10.2 & 9.5 & - & - \\
\hline
\end{tabular}

FU, follow-up; WW, watch and wait; RS, radical surgery.

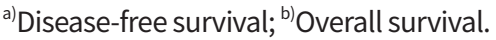


been reported to have a very good prognosis [11-14]. Therefore, if CR can be diagnosed clinically, careful implementation of organ-preserving with WW may be attempted.

Many studies compared oncologic outcomes between patients who underwent WW with those who underwent radical resection (Table 1) [15-26].

We cannot discuss WW without mentioning the Habr-Gama series. Habr-Gama, a pioneer in WW, first proposed WW for treating rectal cancer patients with CCR after PCRT in 2004 [18]. With this approach, survival outcomes were found to be comparable to those with radical surgery. The 5-year disease-free survival (DFS) and overall survival (OS) rates after cCR in the WW group were $92 \%$ (vs. $83 \%$ in the radical surgery group) and $100 \%$ (vs. $88 \%$ in the radical surgery group), respectively. Habr-Gama obtained the same conclusions from the extended cohort [27-30]. Since then, several other studies have reported similar long-term cancer-related survival or OS with WW in comparison with radical resection.

Smith et al. [31] reported the retrospective data of 113 patients who achieved CCR after PCRT using WW strategies. The 5-year DFS was significantly lower in those who underwent WW (75\%) than in those who achieved pCR after TME (92\%), but this was mainly due to the high local regrowth rate in the WW group (20\%). However, 5 -year DFS was not different between WW and TME for pCR (90\% vs. 98\%), and distant metastasis rate was $8 \%$ in WW patients, which was comparable to that reported for patients attaining pCR after TME (4\%) in their study and the previous reports. Therefore, we can assume that patients with CCR after PCRT would be willing to accept WW strategies based on the benefit of rectal preservation, and the risk of disease progression was at the expected level. However, a high local regrowth rate is a concern and the strategies for proper surveillance must be actively explored.

Since the number of patients who indicated for WW is small and no definite guidelines regarding when and how to determine CCR with which diagnostic modalities have been provided, conducting randomized controlled trials (RCTs) is challenging for practical and ethical reasons. The supporting data are based mainly on institutional case series and some recent prospective trials implementing various treatment and surveillance strategies. The worldwide interest in WW became the background for the foundation of the International Wait \& Watch Database (IWWD). It was established in 2014 and aimed to collect all available data on organ-preserving strategies and evaluate the benefits, risks, and oncologic safety of these approaches [32]. They reported oncologic out- comes of $880(87 \%)$ patients with cCR among 1,009 patients collected in the database. Distant metastasis was diagnosed in $71(8 \%)$ of 880 patients [33]. The 5 -year OS rate was $85 \%$ (95\% confidence interval $[\mathrm{Cl}], 80.9 \%$ to $87.7 \%$ ) and the 5 -year DFS rate was $94 \%$ (95\% Cl, $91 \%$ to $96 \%)$. The 2-year cumulative incidence of local regrowth was $25.2 \%$. They reported, using conditional survival analysis estimates, that patients who sustained a cCR for 3 years had a less than $2 \%$ risk of developing systemic recurrence thereafter during the median long-term follow-up of 55.2 months [34]. Habr-Gama group [35] also studied recurrence risk over time and she reported that recurrence has been known to occur within the first 2 or 3 years after completion of surgery in rectal cancer patients who received PCRT and usually patients who are disease-free for an initial 2 or 3 years, seem disease-free for a long time.

Based on previous reports, it has been proved that WW strategies provide significantly higher sphincter preservation without compromising OS and DFS. However, the high local regrowth rate needs to be improved, and the detection of local regrowth at optimal timing for salvage remains the main challenge.

\section{PATTERN OF FAILURE AFTER WW}

When WW fails, we encounter problems that are difficult to handle, such as diagnosing local regrowth and deciding the timing to provide salvage. Indeed, many patients were reluctant to undergo salvage surgery for fear of surgery or stoma. A high local recurrence rate (15\% to $30 \%$ ) is an important oncologic concern in patients with CCR who undergo the WW strategy. Studies comparing radical resection for $\mathrm{PCR}$ reported significantly higher local recurrence rates in the WW group. This was mainly due to local regrowth. This might be caused by an inaccurate diagnosis of $c C R$. The assessment of $C C R$ is usually performed using a combination of digital rectal examination (DRE), flexible endoscopy, and magnetic resonance imaging (MRI) [10,14,18,36-38]. Although the experience and accuracy of these techniques are increasing, the accuracy of diagnosing CCR is not satisfactory because the detection of small foci of residual tumor cells or lymph node involvement is difficult with these techniques.

Little is known about the predictive factors of local regrowth. The InterCoRe consortium evaluated the factors affecting local regrowth after WW for patients with a CCR following chemoradiotherapy in rectal cancer from the data of 11 studies including 605 patients with a median follow-up of 37.6 months [39]. In this meta-analysis, increasing cT stage 
was reported to be associated with an increased risk of local regrowth. Predictive factors for local regrowth may be used to set surveillance timely; therefore, we need to try to identify predictive factors of local recurrence in CCR patients using the WW approach.

To detect local recurrence for performing optimal salvage, proper timing and identifying the location of local recurrence is important. The majority of local recurrences occurred within the first 2 to 3 years after the start of the WW strategy, and intraluminal recurrence consisted of $80 \%$ to $90 \%$ of local recurrences. The IWWD reported that $24 \%$ of the cases showed local regrowth and $88 \%$ occurred within 2 years. Among regrowth cases, 97\% were confined within the bowel wall [33]. Smith et al. [31] reported a $20 \%$ local regrowth rate in their retrospective study. Of the 22 regrowths, 19 (86\%) had an endoluminal component detectable on DRE and endoscopy in the absence of symptoms. Wang et al. [40] conducted a propensity score matching analysis of WW with radical resection for patients with cCR after PCRT. During the median follow-up of 38.2 months (interquartile range [IQR], 25.9 to 52.4 ), 14 patients in the WW group had local regrowth, of which 13 (92.9\%) were located in the bowel wall and one (7.1\%) was located in the regional lymph nodes. These local recurrence patterns, which are mainly localized to intraluminal growth, would be more eligible than extraluminal pelvic local recurrence.

Unmanageable pelvic recurrence is troublesome and results in frustrating oncological outcomes and poor quality of life [4143]. The prevalence of the unsalvageable disease is quite low among local recurrences, although the salvage rate varies from $50 \%$ to $100 \%$ according to the previous studies (Table 2) $[14,17,22,23,28,31,33,39,40,42,44-46]$. The OnCoRe project [23] also reported a high salvage rate of $88 \%$, which was similar to that described by Chadi et al. [39] (89\%) and the HabrGama group (90\%) [28]. Smith et al. [31] reported that timely surgical salvage could be performed in 20 of $22(90 \%)$ patients with local regrowth and 111 of 113 (98\%) overall, with careful surveillance. However, other studies reported salvage rates lower than $70 \%$, with $68.6 \%$ as described by On et al. [45] and $69 \%$ reported in the IWWD [33]. However, the rate of "technically" unsalvageable disease was quite low in most of the reports, and we need to consider that even radical resection could not guarantee absolute local control even for patients

Table 2. Salvage surgery for patients with local regrowth who undergo watch and wait strategy

\begin{tabular}{|c|c|c|c|c|c|c|c|}
\hline Study & Year & Patients & $\begin{array}{l}\text { Regrowth } \\
\text { (\%) }\end{array}$ & $\begin{array}{l}\text { Luminal } \\
\text { regrowth } \\
\text { only (\%) }\end{array}$ & $\begin{array}{c}\text { Salvage } \\
\text { surgery } \\
(\%)\end{array}$ & Type of salvage surgery (\%) & $\begin{array}{l}\text { Disease-free } \\
\text { survival (\%) }\end{array}$ \\
\hline Maas et al. [22] & 2011 & 21 & 4.7 & 4.7 & 100 & Transanal endoscopic microsurgery & $89^{\text {a) }}$ \\
\hline Habr-Gama et al. [28] & 2014 & 71 & 31 & 92.8 & 89.2 & APR (44), AR (28), local excision (28) & $88^{\mathrm{b})}$ \\
\hline Renehan et al. [23] & 2016 & 129 & 34 & 93.2 & 84 & APR (49), AR (20), other resection (7) & 96 (3-year OS) \\
\hline Kong et al. [42] & 2017 & 370 & 28.4 & - & 83.8 & - & \\
\hline van der Valk et al. [33] & 2018 & 1,000 & 25.2 & 97 & 86 & TME (78), local excision (22.3) & $85^{\mathrm{d})}$ \\
\hline Chadi et al. [39] & 2018 & 602 & 28 & - & 89 & - & $87^{\mathrm{d})}$ \\
\hline Dattani et al. $[44]^{\mathrm{e}}$ & 2018 & 692 & 22.1 & - & 88 & Sphincter preservation (45.3) & $93.5^{\mathrm{b})}$ \\
\hline On et al. $[45]^{\mathrm{e})}$ & 2019 & 248 & 12.1 & 80 & 83.3 & $\begin{array}{l}\text { APR (40), LAR(20), other resection (8), local } \\
\text { excision ( } 28)\end{array}$ & - \\
\hline Smith et al. [31] & 2019 & 113 & 19.4 & 86 & 100 & $\begin{array}{l}\text { APR (41), LAR (41), local excision (9), other } \\
\text { resection (9) }\end{array}$ & $75^{\mathrm{d})}$ \\
\hline Park et al. [14] & 2019 & 42 & 28.2 & 77.8 & 88.9 & $\begin{array}{l}\text { APR (25), sphincter saving resection (37.5), } \\
\text { local excision ( } 25)\end{array}$ & - \\
\hline van der Sande et al. [46] & 2020 & 385 & 23.1 & 73 & 94.4 & $\begin{array}{l}\text { APR (27.4), LAR (40.5), local excision (30.9), } \\
\text { induction CTx+CRT+APR (1.2) }\end{array}$ & $90.3^{\mathrm{a})}$ \\
\hline Beard et al. [17] & 2020 & 53 & 11.3 & - & 66.7 & APR (50), LAR (50) & $95^{f)}$ \\
\hline Wang et al. [40] & 2021 & 94 & 14.9 & 92.9 & 85.7 & APR (41.7) & $88^{\mathrm{g})}$ \\
\hline
\end{tabular}

APR, abdominoperineal resection; AR, anterior resection; OS, overall survival; TME, total mesorectal excision; LAR, low anteriorresection; CTx, chemotherapy; CRT, chemoradiotherapy.

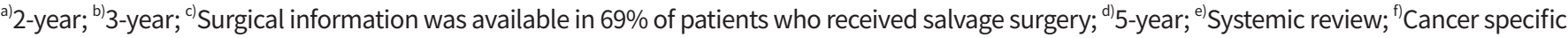

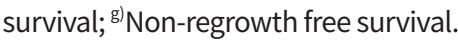


with pCR, as meta-analysis reported a $2.8 \%$ local recurrence rate in this group of patients [47].

In the era of the WW approach, the focus has shifted to local recurrence than distant metastasis. A study comparing local excision with radical resection for $\mathrm{T} 1$ rectal cancer reported that the risk of distant metastasis increased in patients who did not receive radical resection [48-51]. Thus, it is likely that the risk of distant metastasis following WW increases. However, in patients with $\mathrm{CCR}$, distant metastasis following WW was reported to be comparable to that after radical resection in patients with $p C R$ in many studies [16,18,22,24,25]. In a recent meta-analysis of 17 reports [52], the pooled data demonstrated a $9.2 \%$ risk of distant metastasis in the total group, $23.1 \%$ in the local recurrence subgroup, and $5.5 \%$ in the non-local recurrence subgroup. The risk of additional distant metastasis attributed to the omission of immediate surgery was low at $3.0 \%$. This might be because selected patients with favorable tumor characteristics would undergo WW strategies.

However, the timing of distant metastasis might be different and related to local recurrence, and we need to consider the relationship between local recurrence and distant metastasis for surveillance.

\section{LIMITATION IN EVALUATION OF TUMOR RESPONSE}

Although non-operative management appears attractive in both oncologic and functional aspects, it also has limitations for application in real practice, including diagnostic method of $\mathrm{CCR}$, follow-up guidelines, and lack of evidence in the treatment of failed cases. In many reports, CCR was compatible with PCR in only a small proportion of patients. Imaging modalities, including MRI, computed tomography, and positron emission tomography (PET), do not have sufficient accuracy to diagnose cCR. The best diagnostic test for response assessment after PCRT remains controversial. However, MRI has gained consensus as a standard method among the imaging modalities used for local staging [53].

The role of MRI in evaluating the response to PCRT in rectal cancer has focused on the detection of the clinical complete response of primary tumors. A pooled analysis reported that MRI had $75 \%$ accuracy, $95 \%$ sensitivity, $31 \%$ specificity, $83 \%$ positive predictive values, and $47 \%$ negative predictive values to detect CCR [54]. Based on these results, we may assume that MRI can be more useful in ruling out CCR rather than determining CCR. To improve the diagnostic accuracy of
CCR using MRI, diffusion-weighted imaging-MRI, which provides a functional assessment of the tissues, was also tested; however, its efficacy in confirming CCR was unclear [38,5557].

For the evaluation of tumor response to PCRT, two methods are generally used: tumor downstaging based on pre-PCRT clinical stage and MRI-based tumor regression grade (mrTRG) based on morphologic changes (Fig. 1). Tumor downstaging was applied earlier than mrTRG; however, it showed considerable differences with pathologic tumor stage, even only for the primary tumor stage between the clinical and pathological stages because current imaging modalities are not accurate enough for clinical staging and lack of standardization of clinical staging criteria.

Tumor regression does not always result in tumor downstaging. Therefore, TRG was adapted to evaluate the amount of residual tumor. mrTRG was developed to mimic the pathologic TRG. The 5-tier system is usually applied; however, it is difficult to differentiate trivial morphological changes, and the consistency between mrTRG and pathologic TRG was quite variable with differences of $7 \%$ to $29 \%$ (Fig. 2) [36,58-70]. Therefore, recently, a more simplified form of mrTRG was suggested to discriminate between good and poor responders.

The response evaluation time was also important for detecting CCR. Long-term delay to surgery following the completion of PCRT is associated with an increased likelihood of achieving a pCR. Gambacorta et al. [71]. conducted a pooled analysis of seven international randomized trials to evaluate the optimal time to obtain the highest rate of $\mathrm{pCR}$ after PCRT. According to the pooled analysis, the cumulative $\mathrm{PCR}$ rate increased significantly when the interval to surgery lengthened, with $95 \%$ of pCR events within 10 weeks after completion of PCRT. Therefore, close to 10 weeks after PCRT, more CCR would be detected. MRI findings also showed serial changes according to the increased interval after PCRT. Therefore, we need to standardize the time point of response evaluation to determine the most optimal method to confirm the response to PCRT [72].

Although MRI is widely accepted as the standard method of response evaluation to PCRT for rectal cancer, there are still concerns regarding the advantages and disadvantages of each modality, and how to interpret inconsistency among imaging studies is still required to find a more effective and accurate method to evaluate tumor response. In addition, a combination of physical examination, endoscopy, and MRI findings was used to determine the regression level to overcome the limitations of one diagnostic modality. Ko et al. [73] 
Before preoperative

mrTRG 1

Absence of tumor signal and barely visible treatment-related scar

\section{MrTRG 2}

Predominant low signal intensity fibrosis with no obvious residual tumor signal

\section{mrTRG 3}

Low signal intensity fibrosis predominates with obvious areas of intermediate signal intensity

\section{mrTRG 4}

Limited areas of low signal intensity fibrosis or mucin but mostly tumor
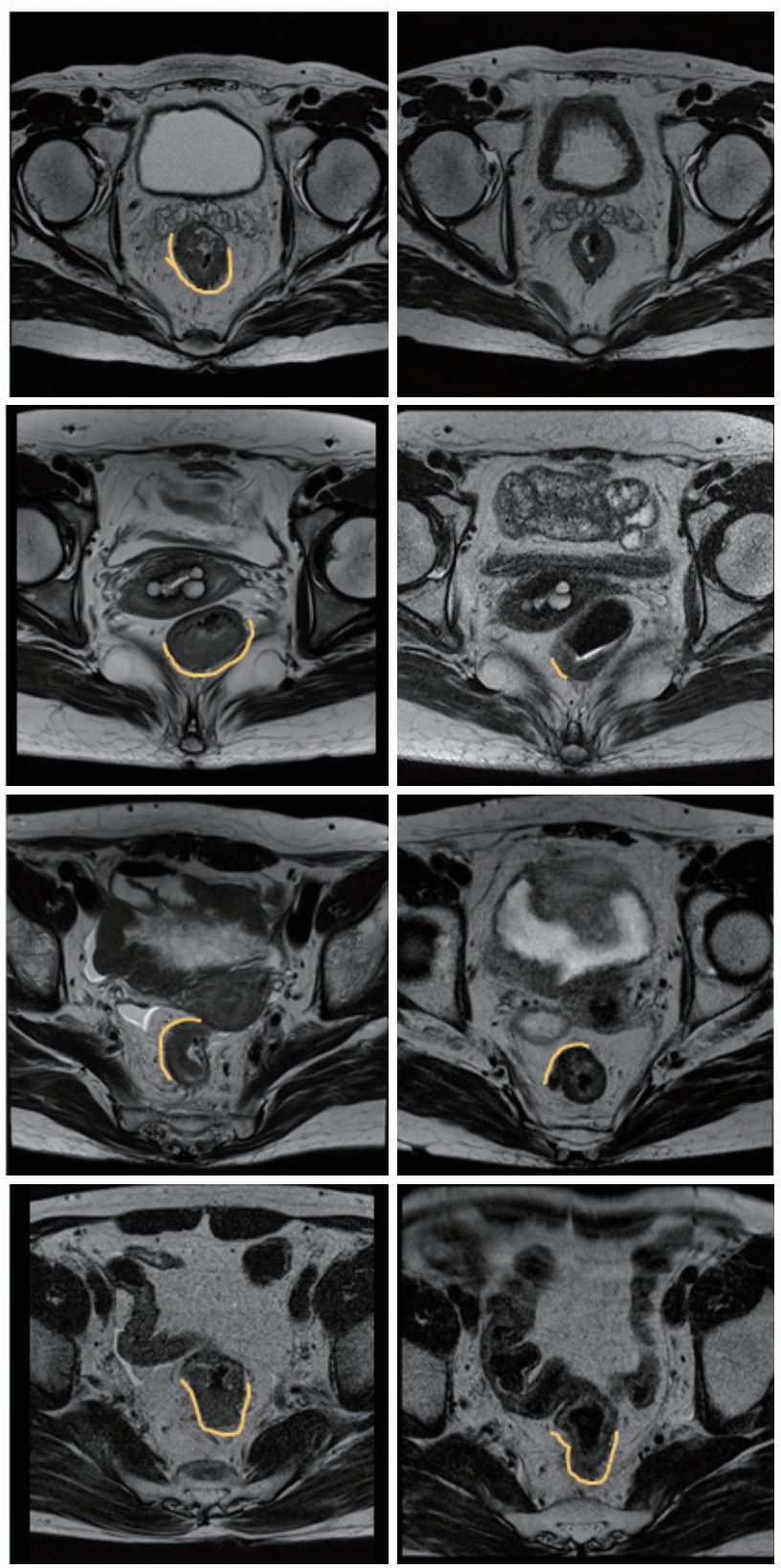

Fig. 1. Magnetic resonance imaging based tumor regression grade (mrTRG). mrTRG categorized tumor regression extent using tumor characteristics and degree of fibrosis, similar to the pathologic tumor regression grade system.

reported that a combination of endoscopy and T2 weighted-MRI increased the identification rate of CR and indicated a $92.6 \%$ correction rate in these cases. Crimi et al. [74] attempted to combine morphologic changes identified with MRI and functional information with PET and showed that the mean standardized uptake values of PET had a significant positive correlation with pathologic TRG $(\rho=0.480$; $P=0.037$ ) and could be used as a complementary method to MRI for response evaluation. There have been studies on the development of genetic biomarkers for response evaluation [75-78] combined with imaging results.

The rate of lymph node metastasis was up to $16 \%$ after PCRT in patients with cCR of the primary tumor $[13,41,61,79]$. Previously studied methods for response evaluation generally focused on the primary tumor response. The accuracy of lymph node evaluation was much more limited, the optimal criteria for malignant lymph nodes were not clearly defined, and studies were heterogeneous [80-82]. The metastatic lymph 


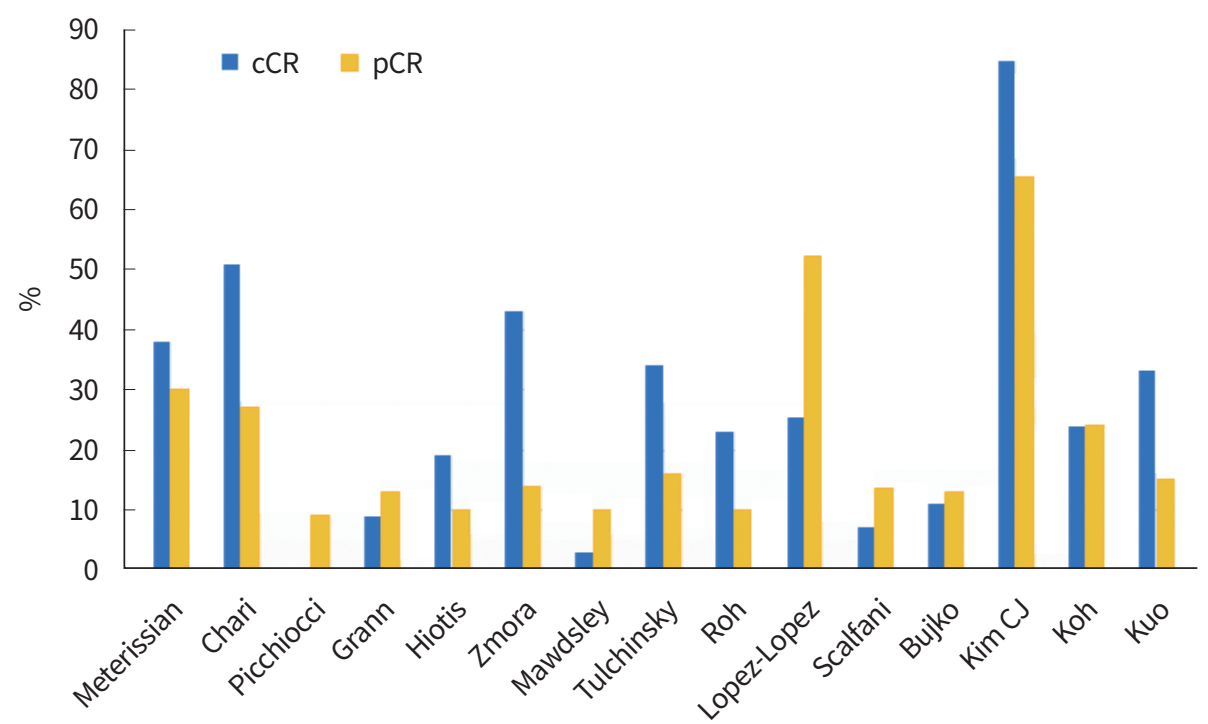

Fig. 2. Consistency between pathologic and clinical complete tumor regression. It showed various discrepancies among studies. cCR, clinical complete regression; $\mathrm{pCR}$, pathologic complete regression.

Table 3. Tumor regression and oncologic outcomes after total neoadjuvant therapy for rectal cancer in prospective trials: comparison with preoperative chemoradiotherapy

\begin{tabular}{|c|c|c|c|c|c|c|c|c|c|c|c|c|}
\hline \multirow{2}{*}{ Study } & \multirow{2}{*}{ Year } & \multicolumn{2}{|c|}{ Number } & \multirow[t]{2}{*}{ TNT type } & \multicolumn{2}{|c|}{ pCR (\%) } & \multicolumn{2}{|c|}{$\begin{array}{c}\text { Local } \\
\text { recurrence (\%) }\end{array}$} & \multicolumn{2}{|c|}{$\begin{array}{c}\text { Distant } \\
\text { metastasis (\%) }\end{array}$} & \multicolumn{2}{|c|}{$\begin{array}{c}\text { Overall } \\
\text { survival (\%) }\end{array}$} \\
\hline & & TNT & PCRT & & TNT & PCRT & TNT & PCRT & TNT & PCRT & TNT & PCRT \\
\hline GCR 3 [96] & 2010 & 56 & 52 & Induction & 14 & 13 & 5 & 2 & 23 & 22 & $75^{\mathrm{a})}$ & $78^{\mathrm{a})}$ \\
\hline Bhatti [97] & 2015 & 65 & 47 & Induction & - & - & 18.4 & 23.4 & 24.6 & 25.5 & $70^{a)}$ & $47^{\text {a) }}$ \\
\hline POLISH II [94] & 2016 & 261 & 254 & Consolidation & 16 & 12 & 22 & 21 & 30 & 27 & 73 & 65 \\
\hline RAPIDO [93] & 2021 & 462 & 450 & Consolidation & 28.4 & 14.3 & 8.3 & 6 & 20 & 26.8 & 89.1 & 88.8 \\
\hline PRODIGE-23 [95] & 2021 & 231 & 230 & Induction & 27.8 & 12.1 & 4 & 6 & 21.2 & 28.3 & 91 & 88 \\
\hline
\end{tabular}

TNT, total neoadjuvant therapy; PCRT, preoperative chemoradiotherapy; pCR, pathologic complete regression; GCR 3, Grupo Cáncer de Recto 3 Study; RAPIDO, Rectal cancer And Preoperative Induction therapy followed by Dedicated Operation; PRODIGE, Partenariat de Recherche en Oncologie Digestive.

a) 5-year overall survival, others are 3-year overall survival.

node is a potent determinant of prognosis. Lymph node metastasis was relatively associated with tumor depth; therefore, patients with $\mathrm{pCR}$ would have a low possibility of lymph node metastasis $[13,83]$. However, many reports have shown worse oncologic outcomes in patients with metastatic lymph nodes, even in PCR patients. Therefore, we must consider lymph node status together to evaluate the response after PCRT. We need to determine how to evaluate lymph node status after PCRT as well as the primary tumor response.

\section{THE ROLE OF TNT IN THE ERA OF WW}

Improving the $\mathrm{CCR}$ rate has become more interesting as the interest in WW increases. Various methods for improving CCR have been tested by modifying radiotherapy or chemotherapy. The simplest approach is to extend the time between the completion of PCRT and reassessment. Several studies have shown that extending the interval between chemoradiotherapy and surgery increased pCR rates [65,84-87]. Most patients who were indicated to undergo PCRT had locally advanced recurrent cancer, and the risk of distant metastasis was rather high [88]. Therefore, progression of disease or micrometastasis over a long interval without any treatment was considered. In the patients who did not receive PCRT, delay in adjuvant chemotherapy has been known to adversely impact colonic and rectal cancer survival, whereas completion of PCRT is associated with improved oncologic outcomes [89-91]. In order to reduce distant metastasis in pa- 


\section{PRECISION AND FUTURE MIEDICINE}

Watch and wait

tients who received PCRT, TNT has emerged and increased because patients who undergo PCRT have the potential to develop WW strategies [34,92-96]. TNT has benefits in terms of improving compliance, better tolerability, and possible earlier treatment of micrometastatic disease.

As the TNT protocol has not yet been established, various methods are being tested (Table 3) [93-97]. Prospective trials combining short-/or long-course radiotherapy and consolidation/induction chemotherapy have been conducted and have reported promising results. Recently, two noticeable RCTs conducted by expert cooperative groups, including the Rectal cancer And Preoperative Induction therapy followed by Dedicated Operation (RAPIDO) and Partenariat de Recherche en Oncologie Digestive (PRODIGE) 23 trials, reported results $[93,95]$. RAPID was an international collaboration driven by the Dutch Colorectal Cancer Group (DCCG) and the Nordic Gastrointestinal Tumour Adjuvant Therapy Group (NGTATG), and PRODIGE was by French national study supported by the Unicancer Gastrointestinal, F'ed'eration Francophone de Canc'erologie Digestive (FFCD), Groupe Coop'erateur Multidisciplinaire en Oncologie (GERCOR), and Groupe Francais Chirurgie du Rectum (GRECCAR). The RAPIDO trial compared short-course radiotherapy followed by six cycles of capecitabine and oxaliplatin (CAPOX) to long-cycle CRT with capecitabine, and no adjuvant chemotherapy was administered to the TNT arm. In PRODIGE23, TNT included 12 weeks of upfront triplet chemotherapy (i.e., modifiend FOLFIRINOX: oxaliplatin, leucovorin, irinotecan, and fluorouracil [mFOLFIRINOX]) followed by CRT, surgery, and 12 weeks of adjuvant chemotherapy (fluoropyrimidines with or without oxaliplatin). The differences between the two trials were the type of neoadjuvant chemotherapy (induction vs. consolidation), duration of radiotherapy (short vs. long-course), and adjuvant chemotherapy.

In the RAPIDO trial [93], disease-related treatment failure including progression, R2 resection, recurrence, new primary colorectal cancer, cancer- or treatment-related death occurring at 3 years in $23.7 \%$ of patients treated with TNT and $30.4 \%$ of those who had received standard therapy (hazard ratio [HR], 0.75; $\mathrm{P}=0.019)$. Serious adverse events occurred similarly in both groups. Although local recurrence was reported to be higher in the TNT arm (17\% vs. $10 \%)$, distant metastasis occurred less frequently in the TNT arm (67\% vs. $81 \%$ ). The PRODIGE 23 set the 3-year DFS rate as the primary endpoint, which was $76 \%$ in the TNT group and $69 \%$ in the standard-of-care group (stratified HR, 0.69; $95 \% \mathrm{Cl}, 0.49$ to $0.97 ; \mathrm{P}=0.034)$ at a median follow-up of 46.5 months (IQR,
35.4 to 61.6). Both studies showed consistent results in terms of pCR rate, which was significantly higher in the TNT group than in the control group ( $28.4 \%$ vs. $14.3 \%$ in RAPIDO, $27.8 \%$ vs. $12.1 \%$ in PRODIGE 23) and decreased risk of 3-year distant metastasis rate ( $7 \%$ vs. relative risk $25 \%$ ). Although many questions about TNT remain unanswered, we assume that TNT would be introduced rapidly in the era of PCRT based on the results from these trials.

Organ Preservation in Rectal Adenocarcinoma (OPRA) phase II trial compared the outcomes between induction and consolidation chemotherapy directly [98]. Patients assigned to the investigation arm received systemic chemotherapy using an induction approach (INCT; before PCRT) or a consolidation approach (CNCT; after PCRT). The decision for TME or WW was based on restaging with DRE, MRI, endoscopy, and/ or biopsy, and TME was recommended for patients with no clinical response. In the interim results [99], they found no difference in DFS between patients treated with TNT and selective WW or TME, compared to historical controls treated with CRT, TME, and adjuvant chemotherapy. The order of PCRT and systemic chemotherapy did not affect survival outcomes; the 3-year DFS between the INCT and CNCT arms did not differ $(77 \%$ vs. $78 \%, \mathrm{P}=0.63)$. However, the time to TMEfree period was significantly higher in the CNCT group, and patients who received PCRT followed by systemic chemotherapy were more likely to preserve the rectum compared to patients treated with systemic chemotherapy first. They also categorized patients into three groups according to clinical response (complete, incomplete, and near-complete) and analyzed DFS, OS, and organ preservation. In patients with near-complete response, OS was comparable to that of the patients with clinical complete response, and more than half (52\%) achieved organ preservation at 3 years. The OPRA trial suggests the effect of TNT in terms of organ preservation and a more favorable sequence of treatment; however, the survival benefit of TNT remains unclear.

Previously reported and ongoing trials reported the advantage of TNT in terms of organ preservation and distant metastasis control consistently; therefore, TNT would be more popular in applying the WW strategy. However, the treatment sequence, benefit on OS, and detection and management of local regrowth still need to be further evaluated.

\section{SURVEILLANCE}

Lack of consensus and expertise in surveillance strategies for patients undergoing WW strategy after PCRT is one of the 
major limitations for clinical practice. It is also challenging to make patients adhere to the surveillance. Another barrier in the community is the lack of insurance coverage for interval endoscopy and MRI. Clarification criteria for patient selection and lowering local regrowth rates would improve acceptance and make this approach more generalizable.

Without a clear guideline, most centers performed intensive follow-up in the WW group comparing with patients who underwent radical resection, especially in the first 2 years $[22,24,30,84,100,101]$. In addition to surveillance of distant metastasis, endoscopy is the main tool for follow-up evaluation for the detection of local regrowth, and MRI has been increasingly used. The utility of performing additional biopsies is highly controversial because the false-negative rate is high and residual disease could not be confirmed with negative biopsy results $[37,59,102]$.

In the initial 1 to 2 years after the WW approach, surveillance was focused on the detection of local regrowth because it was troublesome and caused frequent failures in the WW approach. However, current modalities with endoscopy and MRI have limitations in detecting local regrowth and cannot be compensated with frequent examinations. Therefore, we need to establish a surveillance protocol carefully considering the risk factors of distant metastasis as well as local regrowth and timing of recurrence. We also have to make an effort to find other surveillance methods for complementary imaging modalities, such as genetic biomarkers or combined protocols.

\section{CONCLUSION}

WW approaches are an extreme form of treatment for rectal cancer, which can be carefully applied to a subset of patients. Previous evidence has indicated that WW has comparable long-term oncologic outcomes compared with radical resection for patients with cCR or near CR. TNT was successful in achieving cCR/pCR in more patients. Supporting data for WW applications has increased. However, we must consider that we might be deprived of a chance of curative surgical treatment by applying WW in some patients. Radical resection is considered a standard treatment of choice to overcome various limitations in diagnosis, surveillance, or salvage treatment for CCR after neoadjuvant chemoradiotherapy for rectal cancer.

In addition, improving the accuracy of diagnosis of $\mathrm{CCR}$ or local regrowth, an efficient biomarker to detect response, and optimal surveillance protocols still need to be solved.
We also tried to determine the treatment sequence that leads to the most effective outcomes and the effect of adjunctive treatmentsagents. Furthermore, we keep in mind that TNT has a risk of overtreatment.

Considering the limitations of applying WW, it is not a general treatment for patients who show a good response to PCRT; however, the application of WW would increase, and we have to prepare to adapt WW in clinical practice wisely.

\section{CONFLICTS OF INTEREST}

No potential conflict of interest relevant to this article was reported.

\section{ORCID}

In Ja Park https://orcid.org/0000-0001-5355-3969

\section{AUTHOR CONTRIBUTIONS}

Conception or design: IJP.

Acquisition, analysis, or interpretation of data: IJP.

Drafting the work or revising: IJP.

Final approval of the manuscript: IJP.

\section{REFERENCES}

1. Pieniowski E, Palmer GJ, Juul T, Lagergren P, Johar A, Emmertsen $\mathrm{KJ}$, et al. Low anterior resection syndrome and quality of life after sphincter-sparing rectal cancer surgery: a long-term longitudinal follow-up. Dis Colon Rectum 2019;62:14-20.

2. Sauer R, Liersch T, Merkel S, Fietkau R, Hohenberger W, Hess $C$, et al. Preoperative versus postoperative chemoradiotherapy for locally advanced rectal cancer: results of the German CAO/ARO/AIO-94 randomized phase III trial after a median follow-up of 11 years. J Clin Oncol 2012; 30:1926-33.

3. van Gijn W, Marijnen CA, Nagtegaal ID, Kranenbarg EM, Putter H, Wiggers T, et al. Preoperative radiotherapy combined with total mesorectal excision for resectable rectal cancer: 12-year follow-up of the multicentre, randomised controlled TME trial. Lancet Oncol 2011;12:57582.

4. Kapiteijn E, Marijnen CA, Nagtegaal ID, Putter H, Steup WH, Wiggers T, et al. Preoperative radiotherapy combined with total mesorectal excision for resectable rectal 


\section{PRECISION AND FUTURE MIEDICINE}

Watch and wait

cancer. N Engl J Med 2001;345:638-46.

5. Sauer R, Becker H, Hohenberger W, Rodel C, Wittekind C, Fietkau R, et al. Preoperative versus postoperative chemoradiotherapy for rectal cancer. N Engl J Med 2004;351: 1731-40.

6. Luca F, Craigg DK, Senthil M, Selleck MJ, Babcock BD, Reeves ME, et al. Sexual and urinary outcomes in robotic rectal surgery: review of the literature and technical considerations. Updates Surg 2018;70:415-21.

7. Quah HM, Jayne DG, Eu KW, Seow-Choen F. Bladder and sexual dysfunction following laparoscopically assisted and conventional open mesorectal resection for cancer. Br J Surg 2002;89:1551-6.

8. Eldamshety O, Kotb S, Khater A, Roshdy S, Elashry M, Zahi MS, et al. Early and late functional outcomes of anal sphinctersparing procedures with total mesorectal excision for anorectal adenocarcinoma. Ann Coloproctol 2020;36:148-54.

9. Keller DS, Reali C, Spinelli A, Penna M, Di Candido F, Cunningham $C$, et al. Patient-reported functional and quality-of-life outcomes after transanal total mesorectal excision. Br J Surg 2019;106:364-6.

10. Huh JW, Maeda K, Liu Z, Wang X, Roslani AC, Lee WY. Current status of "Watch-and-Wait" rectal cancer treatment in Asia-Pacific countries. Ann Coloproctol 2020;36: 70-7.

11. Fokas E, Strobel P, Fietkau R, Ghadimi M, Liersch T, Grabenbauer GG, et al. Tumor regression grading after preoperative chemoradiotherapy as a prognostic factor and individual-level surrogate for disease-free survival in rectal cancer. J Natl Cancer Inst 2017;109.

12. Trakarnsanga A, Gonen M, Shia J, Nash GM, Temple LK, Guillem JG, et al. Comparison of tumor regression grade systems for locally advanced rectal cancer after multimodality treatment. J Natl Cancer Inst 2014;106:dju248.

13. Park IJ, You YN, Agarwal A, Skibber JM, Rodriguez-Bigas MA, Eng C, et al. Neoadjuvant treatment response as an early response indicator for patients with rectal cancer. J Clin Oncol 2012;30:1770-6.

14. Park IJ, Lee JL, Yoon YS, Kim CW, Lim SB, Yu CS, et al. Oncologic outcomes of organ preserving approaches in patients with rectal cancer treated with preoperative chemoradiotherapy. Ann Coloproctol 2019;35:65-71.

15. Araujo RO, Valadao M, Borges D, Linhares E, de Jesus JP, Ferreira CG, et al. Nonoperative management of rectal cancer after chemoradiation opposed to resection after complete clinical response. A comparative study. Eur J
Surg Oncol 2015;41:1456-63.

16. Ayloor Seshadri R, Kondaveeti SS, Jayanand SB, John A, Rajendranath R, Arumugam V, et al. Complete clinical response to neoadjuvant chemoradiation in rectal cancers: can surgery be avoided? Hepatogastroenterology 2013;60:410-4.

17. Beard BW, Rettig RL, Ryoo JJ, Parker RA, McLemore EC, Attaluri V. Watch-and-Wait compared to operation for patients with complete response to neoadjuvant therapy for rectal cancer. J Am Coll Surg 2020;231:681-92.

18. Habr-Gama A, Perez RO, Nadalin W, Sabbaga J, Ribeiro U Jr, Silva e Sousa AH Jr, et al. Operative versus nonoperative treatment for stage 0 distal rectal cancer following chemoradiation therapy: long-term results. Ann Surg 2004;240:711-7.

19. Lai CL, Lai MJ, Wu CC, Jao SW, Hsiao CW. Rectal cancer with complete clinical response after neoadjuvant chemoradiotherapy, surgery, or "watch and wait". Int J Colorectal Dis 2016;31:413-9.

20. Lee SY, Kim CH, Kim YJ, Kim HR. Oncologic outcomes according to the treatment strategy in radiologic complete responders after neoadjuvant chemoradiation for rectal cancer. Oncology 2015;89:311-8.

21. Li J, Liu H, Yin J, Liu S, Hu J, Du F, et al. Wait-and-see or radical surgery for rectal cancer patients with a clinical complete response after neoadjuvant chemoradiotherapy: a cohort study. Oncotarget 2015;6:42354-61.

22. Maas M, Beets-Tan RG, Lambregts DM, Lammering G, Nelemans PJ, Engelen SM, et al. Wait-and-see policy for clinical complete responders after chemoradiation for rectal cancer. J Clin Oncol 2011;29:4633-40.

23. Renehan AG, Malcomson L, Emsley R, Gollins S, Maw A, Myint AS, et al. Watch-and-wait approach versus surgical resection after chemoradiotherapy for patients with rectal cancer (the OnCoRe project): a propensity-score matched cohort analysis. Lancet Oncol 2016;17:174-83.

24. Smith JD, Ruby JA, Goodman KA, Saltz LB, Guillem JG, Weiser MR, et al. Nonoperative management of rectal cancer with complete clinical response after neoadjuvant therapy. Ann Surg 2012;256:965-72.

25. Wang XH, Zhou CJ, Zhang S, Wang QX, Xiao WW, Ding $\mathrm{PR}$, et al. Comparison of long-term efficacy between watch and wait strategy and total mesorectal excision in locally advanced rectal cancer patients with clinical complete response after neoadjuvant therapy. Zhonghua Wei Chang Wai Ke Za Zhi 2020;23:266-73.

26. Yeom SS, Lee SY, Kim CH, Kim YJ, Nam TK, Kim HR. 
Non-operative treatment outcome for rectal cancer patient with clinical complete response after neoadjuvant chemoradiotherapy. Asian J Surg 2019;42:823-31.

27. Habr-Gama A, Lynn PB, Jorge JM, Sao Juliao GP, Proscurshim I, Gama-Rodrigues J, et al. Impact of organ-preserving strategies on anorectal function in patients with distal rectal cancer following neoadjuvant chemoradiation. Dis Colon Rectum 2016;59:264-9.

28. Habr-Gama A, Gama-Rodrigues J, Sao Juliao GP, Proscurshim I, Sabbagh C, Lynn PB, et al. Local recurrence after complete clinical response and watch and wait in rectal cancer after neoadjuvant chemoradiation: impact of salvage therapy on local disease control. Int J Radiat Oncol Biol Phys 2014;88:822-8.

29. Habr-Gama A, Perez RO, Wynn G, Marks J, Kessler H, Gama-Rodrigues J. Complete clinical response after neoadjuvant chemoradiation therapy for distal rectal cancer: characterization of clinical and endoscopic findings for standardization. Dis Colon Rectum 2010;53: 1692-8.

30. Habr-Gama A, Sabbaga J, Gama-Rodrigues J, Sao Juliao GP, Proscurshim I, Bailao Aguilar P, et al. Watch and wait approach following extended neoadjuvant chemoradiation for distal rectal cancer: are we getting closer to anal cancer management? Dis Colon Rectum 2013;56:110917.

31. Smith JJ, Strombom P, Chow OS, Roxburgh CS, Lynn P, Eaton A, et al. Assessment of a Watch-and-Wait strategy for rectal cancer in patients with a complete response after neoadjuvant therapy. JAMA Oncol 2019;5:e185896.

32. Beets GL, Figueiredo NL, Habr-Gama A, van de Velde CJ. A new paradigm for rectal cancer: organ preservation. Introducing the International Watch \& Wait Database (IWWD). Eur J Surg Oncol 2015;41:1562-4.

33. van der Valk M, Hilling DE, Bastiaannet E, MeershoekKlein Kranenbarg E, Beets GL, Figueiredo NL, et al. Longterm outcomes of clinical complete responders after neoadjuvant treatment for rectal cancer in the International Watch \& Wait Database (IWWD): an international multicentre registry study. Lancet 2018;391:2537-45.

34. Fernandez LM, Sao Juliao GP, Figueiredo NL, Beets GL, van der Valk M, Bahadoer RR, et al. Conditional recurrence-free survival of clinical complete responders managed by watch and wait after neoadjuvant chemoradiotherapy for rectal cancer in the International Watch \& Wait Database: a retrospective, international, multicentre registry study. Lancet Oncol 2021;22:43-50.
35. Sao Juliao GP, Karagkounis G, Fernandez LM, Habr-Gama A, Vailati BB, Dattani M, et al. Conditional survival in patients with rectal cancer and complete clinical response managed by watch and wait after chemoradiation: recurrence risk over time. Ann Surg 2020;272:138-44.

36. Lopez-Lopez V, Abrisqueta J, Lujan J, Hernandez Q, Ono A, Parrilla P. Utility of rectoscopy in the assessment of response to neoadjuvant treatment for locally advanced rectal cancer. Saudi J Gastroenterol 2016;22:148-53.

37. van der Sande ME, Maas M, Melenhorst J, Breukink SO, van Leerdam ME, Beets GL. Predictive value of endoscopic features for a complete response after chemoradiotherapy for rectal cancer. Ann Surg 2021;274:e541-7.

38. Lambregts DM, Vandecaveye V, Barbaro B, Bakers FC, Lambrecht M, Maas M, et al. Diffusion-weighted MRI for selection of complete responders after chemoradiation for locally advanced rectal cancer: a multicenter study. Ann Surg Oncol 2011;18:2224-31.

39. Chadi SA, Malcomson L, Ensor J, Riley RD, Vaccaro CA, Rossi GL, et al. Factors affecting local regrowth after watch and wait for patients with a clinical complete response following chemoradiotherapy in rectal cancer (InterCoRe consortium): an individual participant data meta-analysis. Lancet Gastroenterol Hepatol 2018;3:82536.

40. Wang QX, Zhang R, Xiao WW, Zhang S, Wei MB, Li YH, et al. The watch-and-wait strategy versus surgical resection for rectal cancer patients with a clinical complete response after neoadjuvant chemoradiotherapy. Radiat Oncol 2021;16:16.

41. Kim CH, Yeom SS, Kwak HD, Lee SY, Ju JK, Kim YJ, et al. Clinical outcomes of patients with locally advanced rectal cancer with persistent circumferential resection margin invasion after preoperative chemoradiotherapy. Ann Coloproctol 2019;35:72-82.

42. Kong JC, Guerra GR, Warrier SK, Ramsay RG, Heriot AG. Outcome and salvage surgery following "Watch and Wait" for rectal cancer after neoadjuvant therapy: a systematic review. Dis Colon Rectum 2017;60:335-45.

43. Nasir I, Fernandez L, Vieira P, Pares O, Santiago I, Castillo-Martin M, et al. Salvage surgery for local regrowths in Watch \& Wait: are we harming our patients by deferring the surgery? Eur J Surg Oncol 2019;45:1559-66.

44. Dattani M, Heald RJ, Goussous G, Broadhurst J, Sao Juliao GP, Habr-Gama A, et al. Oncological and survival outcomes in watch and wait patients with a clinical complete response after neoadjuvant chemoradiotherapy 
for rectal cancer: a systematic review and pooled analysis. Ann Surg 2018;268:955-67.

45. On J, Shim J, Aly EH. Systematic review and meta-analysis on outcomes of salvage therapy in patients with tumour recurrence during 'watch and wait' in rectal cancer. Ann R Coll Surg Engl 2019;101:441-52.

46. van der Sande ME, Figueiredo N, Beets GL. Management and outcome of local regrowths in a watch-and-wait prospective cohort for complete responses in rectal cancer. Ann Surg 2021;274:e1056-62.

47. Maas M, Nelemans PJ, Valentini V, Das P, Rodel C, Kuo LJ, et al. Long-term outcome in patients with a pathological complete response after chemoradiation for rectal cancer: a pooled analysis of individual patient data. Lancet Oncol 2010;11:835-44.

48. Doornebosch PG, Ferenschild FT, de Wilt JH, Dawson I, Tetteroo GW, de Graaf EJ. Treatment of recurrence after transanal endoscopic microsurgery (TEM) for T1 rectal cancer. Dis Colon Rectum 2010;53:1234-9.

49. Bentrem DJ, Okabe S, Wong WD, Guillem JG, Weiser MR, Temple LK, et al. T1 adenocarcinoma of the rectum: transanal excision or radical surgery? Ann Surg 2005;242:4727.

50. Madbouly KM, Remzi FH, Erkek BA, Senagore AJ, Baeslach CM, Khandwala F, et al. Recurrence after transanal excision of T1 rectal cancer: should we be concerned? Dis Colon Rectum 2005;48:711-9.

51. Hwang Y, Yoon YS, Bong JW, Choi HY, Song IH, Lee JL, et al. Long-term transanal excision outcomes in patients with T1 rectal cancer: comparative analysis of radical resection. Ann Coloproctol 2019;35:194-201.

52. Socha J, Kepka L, Michalski W, Paciorek K, Bujko K. The risk of distant metastases in rectal cancer managed by a watch-and-wait strategy: a systematic review and meta-analysis. Radiother Oncol 2020;144:1-6.

53. Beets-Tan R, Lambregts D, Maas M, Bipat S, Barbaro B, Curvo-Semedo $L$, et al. Magnetic resonance imaging for clinical management of rectal cancer: updated recommendations from the 2016 European Society of Gastrointestinal and Abdominal Radiology (ESGAR) consensus meeting. Eur Radiol 2018;28:1465-75.

54. de Jong EA, ten Berge JC, Dwarkasing RS, Rijkers AP, van Eijck $\mathrm{CH}$. The accuracy of MRI, endorectal ultrasonography, and computed tomography in predicting the response of locally advanced rectal cancer after preoperative therapy: a metaanalysis. Surgery 2016;159:688-99.

55. Boone D, Taylor SA, Halligan S. Diffusion weighted MRI: overview and implications for rectal cancer management. Colorectal Dis 2013;15:655-61.

56. Lambregts DM, Lahaye MJ, Heijnen LA, Martens MH, Maas $M$, Beets $G L$, et al. MRI and diffusion-weighted MRI to diagnose a local tumour regrowth during long-term follow-up of rectal cancer patients treated with organ preservation after chemoradiotherapy. Eur Radiol 2016;26:2118-25.

57. Song I, Kim SH, Lee SJ, Choi JY, Kim MJ, Rhim H. Value of diffusion-weighted imaging in the detection of viable tumour after neoadjuvant chemoradiation therapy in patients with locally advanced rectal cancer: comparison with $\mathrm{T} 2$ weighted and PET/CT imaging. $\mathrm{Br} \mathrm{J}$ Radiol 2012;85:577-86.

58. Chari RS, Tyler DS, Anscher MS, Russell L, Clary BM, Hathorn J, et al. Preoperative radiation and chemotherapy in the treatment of adenocarcinoma of the rectum. Ann Surg 1995;221:778-86.

59. Hiotis SP, Weber SM, Cohen AM, Minsky BD, Paty PB, Guillem JG, et al. Assessing the predictive value of clinical complete response to neoadjuvant therapy for rectal cancer: an analysis of 488 patients. J Am Coll Surg 2002; 194:131-5.

60. Kim CJ, Yeatman TJ, Coppola D, Trotti A, Williams B, Barthel JS, et al. Local excision of T2 and T3 rectal cancers after downstaging chemoradiation. Ann Surg 2001;234: 352-8.

61. Koh DM, Chau I, Tait D, Wotherspoon A, Cunningham D, Brown G. Evaluating mesorectal lymph nodes in rectal cancer before and after neoadjuvant chemoradiation using thin-section T2-weighted magnetic resonance imaging. Int J Radiat Oncol Biol Phys 2008;71:456-61.

62. Kuo LJ, Chiou JF, Tai CJ, Chang CC, Kung CH, Lin SE, et al. Can we predict pathologic complete response before surgery for locally advanced rectal cancer treated with preoperative chemoradiation therapy? Int J Colorectal Dis 2012;27:613-21.

63. Mawdsley S, Glynne-Jones R, Grainger J, Richman P, Makris A, Harrison M, et al. Can histopathologic assessment of circumferential margin after preoperative pelvic chemoradiotherapy for T3-T4 rectal cancer predict for 3-year disease-free survival? Int J Radiat Oncol Biol Phys 2005;63:745-52.

64. Meterissian S, Skibber J, Rich T, Roubein L, Ajani J, Cleary K, et al. Patterns of residual disease after preoperative chemoradiation in ultrasound $\mathrm{T} 3$ rectal carcinoma. Ann Surg Oncol 1994;1:111-6.

65. Tulchinsky H, Shmueli E, Figer A, Klausner JM, Rabau M. 
An interval $>7$ weeks between neoadjuvant therapy and surgery improves pathologic complete response and disease-free survival in patients with locally advanced rectal cancer. Ann Surg Oncol 2008;15:2661-7.

66. Zmora O, Dasilva GM, Gurland B, Pfeffer R, Koller M, Nogueras JJ, et al. Does rectal wall tumor eradication with preoperative chemoradiation permit a change in the operative strategy? Dis Colon Rectum 2004;47:160712.

67. Bujko K, Richter P, Kolodziejczyk M, Nowacki MP, Kulig J, Popiela T, et al. Preoperative radiotherapy and local excision of rectal cancer with immediate radical re-operation for poor responders. Radiother Oncol 2009;92:195201.

68. Roh MS, Colangelo LH, O'Connell MJ, Yothers G, Deutsch M, Allegra $\mathrm{CJ}$, et al. Preoperative multimodality therapy improves disease-free survival in patients with carcinoma of the rectum: NSABP R-03. J Clin Oncol 2009;27:5124-30.

69. Grann A, Feng C, Wong D, Saltz L, Paty PP, Guillem JG, et al. Preoperative combined modality therapy for clinically resectable UT3 rectal adenocarcinoma. Int J Radiat Oncol Biol Phys 2001;49:987-95.

70. Sclafani F, Brown G, Cunningham D, Wotherspoon A, Mendes L, Balyasnikova S, et al. Comparison between MRI and pathology in the assessment of tumour regression grade in rectal cancer. Br J Cancer 2017;117:147885.

71. Gambacorta MA, Masciocchi C, Chiloiro G, Meldolesi E, Macchia G, van Soest J, et al. Timing to achieve the highest rate of $\mathrm{pCR}$ after preoperative radiochemotherapy in rectal cancer: a pooled analysis of 3085 patients from 7 randomized trials. Radiother Oncol 2021;154:154-60.

72. Park SH, Cho SH, Choi SH, Jang JK, Kim MJ, Kim SH, et al. MRI assessment of complete response to preoperative chemoradiation therapy for rectal cancer: 2020 guide for practice from the Korean Society of Abdominal Radiology. Korean J Radiol 2020;21:812-28.

73. Ko HM, Choi YH, Lee JE, Lee KH, Kim JY, Kim JS. Combination assessment of clinical complete response of patients with rectal cancer following chemoradiotherapy with endoscopy and magnetic resonance imaging. Ann Coloproctol 2019;35:202-8.

74. Crimi F, Stramare R, Spolverato G, Aldegheri V, Barison A, D'Alimonte L, et al. T2-weighted, apparent diffusion coefficient and 18F-FDG PET histogram analysis of rectal cancer after preoperative chemoradiotherapy. Tech Coloproctol 2021;25:569-77.
75. Boysen AK, Schou JV, Spindler KG. Cell-free DNA and preoperative chemoradiotherapy for rectal cancer: a systematic review. Clin Transl Oncol 2019;21:874-80.

76. Jeon BH, Shin US, Moon SM, Choi JI, Kim MS, Kim KH, et al. Neutrophil to lymphocyte ratio: a predictive marker for treatment outcomes in patients with rectal cancer who underwent neoadjuvant chemoradiation followed by surgery. Ann Coloproctol 2019;35:100-6.

77. Cho E, Park IJ, Yeom SS, Hong SM, Lee JB, Kim YW, et al. A multigene model for predicting tumor responsiveness after preoperative chemoradiotherapy for rectal cancer. Int J Radiat Oncol Biol Phys 2019;105:834-42.

78. Xue Z, Yang S, Luo Y, Cai H, He M, Ding Y, et al. A 41-gene pair signature for predicting the pathological response of locally advanced rectal cancer to neoadjuvant chemoradiation. Front Med (Lausanne) 2021;8:744295.

79. Kim MJ, Jeong SY, Park JW, Ryoo SB, Cho SS, Lee KY, et al. Oncologic outcomes in patients who undergo neoadjuvant chemoradiotherapy and total mesorectal excision for locally advanced rectal cancer: a 14-year experience in a single institution. Ann Coloproctol 2019;35:8393.

80. Beets-Tan RG, Lambregts DM, Maas M, Bipat S, Barbaro B, Caseiro-Alves $\mathrm{F}$, et al. Magnetic resonance imaging for the clinical management of rectal cancer patients: recommendations from the 2012 European Society of Gastrointestinal and Abdominal Radiology (ESGAR) consensus meeting. Eur Radiol 2013;23:2522-31.

81. Tapan U, Ozbayrak M, Tatli S. MRI in local staging of rectal cancer: an update. Diagn Interv Radiol 2014;20:3908.

82. Tudyka V, Blomqvist L, Beets-Tan RG, Boelens PG, Valentini $V$, van de Velde $C J$, et al. EURECCA consensus conference highlights about colon \& rectal cancer multidisciplinary management: the radiology experts review. Eur J Surg Oncol 2014;40:469-75.

83. Kim HJ, Choi GS. Clinical implications of lymph node metastasis in colorectal cancer: current status and future perspectives. Ann Coloproctol 2019;35:109-17.

84. Kalady MF, de Campos-Lobato LF, Stocchi L, Geisler DP, Dietz D, Lavery IC, et al. Predictive factors of pathologic complete response after neoadjuvant chemoradiation for rectal cancer. Ann Surg 2009;250:582-9.

85. Moore HG, Gittleman AE, Minsky BD, Wong D, Paty PB, Weiser $\mathrm{M}$, et al. Rate of pathologic complete response with increased interval between preoperative combined modality therapy and rectal cancer resection. Dis Colon 


\section{PRECISION AND FUTURE MIEDICINE}

Watch and wait

Rectum 2004;47:279-86.

86. Petrelli F, Sgroi G, Sarti E, Barni S. Increasing the interval between neoadjuvant chemoradiotherapy and surgery in rectal cancer: a meta-analysis of published studies. Ann Surg 2016;263:458-64.

87. Rombouts A, Hugen N, Elferink M, Nagtegaal ID, de Wilt J. Treatment interval between neoadjuvant chemoradiotherapy and surgery in rectal cancer patients: a population-based study. Ann Surg Oncol 2016;23:3593-601.

88. Oh SG, Park IJ, Seo JH, Kim YI, Lim SB, Kim CW, et al. Beware of early relapse in rectal cancer patients treated with preoperative chemoradiotherapy. Ann Coloproctol 2020; 36:382-9.

89. Des Guetz G, Nicolas P, Perret GY, Morere JF, Uzzan B. Does delaying adjuvant chemotherapy after curative surgery for colorectal cancer impair survival? A meta-analysis. Eur J Cancer 2010;46:1049-55.

90. Nachiappan S, Askari A, Mamidanna R, Munasinghe A, Currie A, Stebbing J, et al. The impact of adjuvant chemotherapy timing on overall survival following colorectal cancer resection. Eur J Surg Oncol 2015;41:1636-44.

91. Park YY, Lee KY, Kim NK, Lee SB, Kim GR, Min BS, et al. Impact of adjuvant chemotherapy completion on oncologic outcomes in ypTNMstage 2 rectal cancer patients. Ann Coloproctol 2019;35:335-41.

92. Nasrolahi H, Mirzaei S, Mohammadianpanah M, Bananzadeh AM, Mokhtari M, Sasani MR, et al. Efficacy and feasibility of adding induction chemotherapy to neoadjuvant chemoradiation in locally advanced rectal cancer: a phase II clinical trial. Ann Coloproctol 2019;35:242-8.

93. Bahadoer RR, Dijkstra EA, van Etten B, Marijnen C, Putter $\mathrm{H}$, Kranenbarg EM, et al. Short-course radiotherapy followed by chemotherapy before total mesorectal excision (TME) versus preoperative chemoradiotherapy, TME, and optional adjuvant chemotherapy in locally advanced rectal cancer (RAPIDO): a randomised, open-label, phase 3 trial. Lancet Oncol 2021;22:29-42.

94. Cisel B, Pietrzak L, Michalski W, Wyrwicz L, Rutkowski A, Kosakowska E, et al. Long-course preoperative chemoradiation versus $5 \times 5$ Gy and consolidation chemotherapy for clinical T4 and fixed clinical T3 rectal cancer: long-term results of the randomized Polish II study. Ann Oncol 2019;30:1298-303.

95. Conroy T, Bosset JF, Etienne PL, Rio E, Francois E, Mesgouez-Nebout N, et al. Neoadjuvant chemotherapy with FOLFIRINOX and preoperative chemoradiotherapy for patients with locally advanced rectal cancer (UNICANCER-PRODIGE 23): a multicentre, randomised, open-label, phase 3 trial. Lancet Oncol 2021;22:702-15.

96. Fernandez-Martos C, Pericay C, Aparicio J, Salud A, Safont M, Massuti B, et al. Phase II, randomized study of concomitant chemoradiotherapy followed by surgery and adjuvant capecitabine plus oxaliplatin (CAPOX) compared with induction CAPOX followed by concomitant chemoradiotherapy and surgery in magnetic resonance imaging-defined, locally advanced rectal cancer: grupo cancer de recto 3 study. J Clin Oncol 2010;28:85965.

97. Bhatti AB, Waheed A, Hafeez A, Akbar A, Syed AA, Khattak $S$, et al. Can induction chemotherapy before concurrent chemoradiation impact circumferential resection margin positivity and survival in low rectal cancers? Asian Pac J Cancer Prev 2015;16:2993-8.

98. Smith JJ, Chow OS, Gollub MJ, Nash GM, Temple LK, Weiser MR, et al. Organ preservation in rectal adenocarcinoma: a phase II randomized controlled trial evaluating 3-year disease-free survival in patients with locally advanced rectal cancer treated with chemoradiation plus induction or consolidation chemotherapy, and total mesorectal excision or nonoperative management. BMC Cancer 2015;15:767.

99. Garcia-Aguilar J, Patil S, Kim JK, Yuval JB, Thompson H, Verheij $F$, et al. Preliminary results of the organ preservation of rectal adenocarcinoma (OPRA) trial. J Clin Oncol 2020;38(15 Suppl):4008.

100. Dalton RS, Velineni R, Osborne ME, Thomas R, Harries S, Gee AS, et al. A single-centre experience of chemoradiotherapy for rectal cancer: is there potential for nonoperative management? Colorectal Dis 2012;14:567-71.

101. Lambregts DM, Maas M, Bakers FC, Cappendijk VC, Lammering $\mathrm{G}$, Beets $\mathrm{GL}$, et al. Long-term follow-up features on rectal MRI during a wait-and-see approach after a clinical complete response in patients with rectal cancer treated with chemoradiotherapy. Dis Colon Rectum 2011;54:15218.

102. Kawai K, Ishihara S, Nozawa H, Hata K, Kiyomatsu T, Morikawa T, et al. Prediction of pathological complete response using endoscopic findings and outcomes of patients who underwent watchful waiting after chemoradiotherapy for rectal cancer. Dis Colon Rectum 2017;60: 368-75. 